\title{
Dashed line relaxing retinotomy in the management of retinal detachment with anterior proliferative vitreoretinopathy
}

This article was published in the following Dove Press journal:

Clinical Ophthalmology

2 April 2015

Number of times this article has been viewed

\author{
Chui-Lien Tsen' \\ Yu-Harn Horng' \\ Shwu-Jiuan Sheu', \\ 'Department of Ophthalmology, \\ Kaohsiung Veterans General \\ Hospital, Kaohsiung, Taiwan; ${ }^{2}$ School \\ of Medicine, National Yang-Ming \\ University, Taipei, Taiwan
}

Background: We describe the anatomical and functional outcomes of eyes that underwent a modified technique of relaxing retinotomy, dashed line relaxing retinotomy, in the management of retinal detachment with anterior proliferative vitreoretinopathy.

Methods: We retrospectively reviewed 54 consecutive eyes in 52 patients who received pars plana vitrectomy with relaxing retinotomy during retinal detachment repair. Perfluorocarbon liquid (PFCL) was used as a standard procedure to stabilize the retina during retinotomy to prevent slippage or inversion of the posterior flap. If PFCL was not available due to economic reasons, dashed line relaxing retinotomy was performed instead. Best-corrected visual acuity, slit-lamp biomicroscopy, intraocular pressure measurement, lens status, and fundus examination were analyzed. We excluded patients who were followed up $<4$ months.

Results: Regarding anatomical success rates and visual outcomes, we found no significant differences between patients treated with intraoperative PFCL and those treated with dashed line relaxing retinotomy without PFCL.

Conclusion: Compared to the simple and efficient PFCL-assisted relaxing retinotomy, dashed relaxing retinotomy is not the first choice when PFCL is available. Based on our results, this modified technique may offer an alternative in patients with anterior proliferative vitreoretinopathy for whom PFCL is not available.

Keywords: perfluorocarbon liquid, PFCL

\section{Introduction}

Proliferative vitreoretinopathy (PVR), a process of cellular proliferation and contractile preretinal membrane formation, is the most common cause of failure in retinal detachment (RD) surgery. Current surgical techniques for treatment of PVR-related RD include pars plana vitrectomy with or without scleral buckling, membrane peeling, perfluorocarbon liquid (PFCL) infusion, relaxing retinotomy, retinectomy, anterior base dissection, and intraocular tamponade with gas or silicone oil. The first description of relaxing retinotomy was presented by Machemer in 1979 in the case of an eye with traumatic retinal incarceration. ${ }^{1}$ Since then, relaxing retinotomy has become an important surgical adjunct in cases of complicated RD with PVR when periretinal traction and retinal shortening cannot be relieved by epiretinal membrane dissection or scleral buckling. ${ }^{2,3}$ The peripheral retina was usually excised to preserve the function of the posterior retina, which is more visually significant. Several studies reported the benefit of PFCLs in the management of RD associated with PVR. ${ }^{4-10}$ However, PFCL may not be available for some patients because of reasons such as economic issues. The purpose of this study was to describe the anatomical and functional outcomes of eyes that underwent the modified technique of
Correspondence: Shwu-jiuan Sheu Department of Ophthalmology, Kaohsiung Veterans General Hospital, 386, Ta-Chung Ist Road, Kaohsiung 8I3, Taiwan

Tel +88673468217

Fax +88673468216

Email sjsheu@vghks.gov.tw; sjiuansheu@ gmail.com 
relaxing retinotomy with dashed line relaxing retinotomy in the management of RD with anterior PVR.

\section{Patients and methods}

We retrospectively reviewed the clinical and operative records of 54 consecutive eyes in 52 patients with anterior PVR who received pars plana vitrectomy with relaxing retinotomy during RD repair. Surgical procedures were performed by a single surgeon (SJS) between July 2010 and May 2013 at Kaohsiung Veterans General Hospital, Taiwan. The institutional review board and ethics committee approved this study, which adhered to the tenets of the Declaration of Helsinki. Due to the retrospective nature of this study, patient consent was not required. All patients underwent a comprehensive ophthalmic examination before operation that included best-corrected visual acuity (BCVA), slit-lamp biomicroscopy, intraocular pressure (IOP) measurement, lens status, and fundoscopic examination. We excluded patients who were followed up less than 4 months $(n=4)$. PVR in this study was characterized by a wide-angle viewing system and was graded according to the Retinal Society classification system. ${ }^{11}$

\section{Surgical procedures}

In 13 eyes, PFCL was used to flatten and stabilize the edge of the anterior retinal flap according to the procedure suggested by a previous report. ${ }^{5}$ Forty-one eyes received dashed line relaxing retinotomy without PFCL use, as the patients could not afford the cost of PFCL. We used standard 3-port (or 4-port with additional chandelier light) pars plana vitrectomy to remove the vitreous periphery as necessary. The procedure was performed by 20 - or smaller-gauge vitrectomy. Before relaxing retinotomy, we had to remove the epiretinal or subretinal membrane completely. A wide-angle viewing system was useful to examine the full extent of the retina to decide the area that should be relaxed. We extended the relaxing retinotomy into the normal retina on each end of the area of contraction for about 1 hour. Diathermy was applied to the entire area to be cut in a dashed line pattern. Blood vessels in this area were occluded by cauterization. Fluid gas exchange was performed with an endodrainage through a preexisting break or a new retinotomy at least two disk diameters from the disk, avoiding the macula and large vessels. The relaxing retinotomy was completed by gently tearing the dashed line diathermy on the retina under air phase. The anterior retinal flap was then cut under air phase or silicone oil. At this time, bleeding may occur from the retina or choroid and usually can be controlled either by raising the IOP or cauterizing the bleeding vessels. Laser endophotocoagulation then can be applied to the edges of the retinotomy, if possible, including the anterior margin of the retinotomy. Finally, an air-silicone oil exchange can be done if necessary. Oil exchange is started at high pressure to help flatten the wrinkled posterior retina. The sclerotomies were sutured in 20-gauge vitrectomy (Figure 1).

Data included for statistical analysis were sex, age, diagnosis, extent of relaxing retinotomy, type of intraocular tamponade, additional procedures, and anatomical and functional surgical outcomes. Primary RD was defined as RD without any comorbidity or previous surgery. The reattachment was defined as complete retinal reattachment at least 3 months postoperatively. Visual outcome was defined as the central visual acuity at the last visit. Secondary glaucoma was defined as IOP of $>25 \mathrm{mmHg}$. Hypotony was defined as IOP of $<5 \mathrm{mmHg}$.

The statistical analysis was performed using SPSS version 12.0 (SPSS Inc., Chicago, IL, USA). Descriptive statistics were expressed as mean \pm standard deviation. The Fisher's exact test and Pearson's chi-square test were used to compare the proportions in the $2 \times 2$ groups and contingency tables, respectively. Means of normally distributed variables were compared with the $t$-test. Odds ratio were also calculated. The $P$-value or 95 th percentile confidence interval was shown, as appropriate. Variables not showing a normal distribution were compared using the nonparametric Mann-Whitney $U$-test.

\section{Results}

Summaries of the baseline characteristics and preoperative ophthalmologic findings are listed in Table 1. The study included 54 eyes (52 patients) with mean follow-up period of 22.9 \pm 10.64 months (range: 4-42 months). Combined rhegmatogenous and tractional RD with established PVR secondary to proliferative diabetic retinopathy, trauma, and ocular inflammatory disease were observed in 14 of 54 eyes (26\%).

During our surgical interventions, 15 of 54 eyes (28\%) underwent combined scleral buckling with vitrectomy, and nine eyes $(17 \%)$ underwent combined lensectomy with vitrectomy. Lensectomy was not done in all cases due to health insurance reimbursement policy. Relaxing retinotomy was performed in all cases, and the mean size of relaxing retinotomy was $134.6 \pm 64.6$ degrees (range: 30-360 degrees). Forty of 54 eyes (74\%) received relaxing retinotomy of $<180$ degrees, and the remaining 14 of 54 eyes (26\%) required a relaxing retinotomy $\geq 180$ degrees. For the 

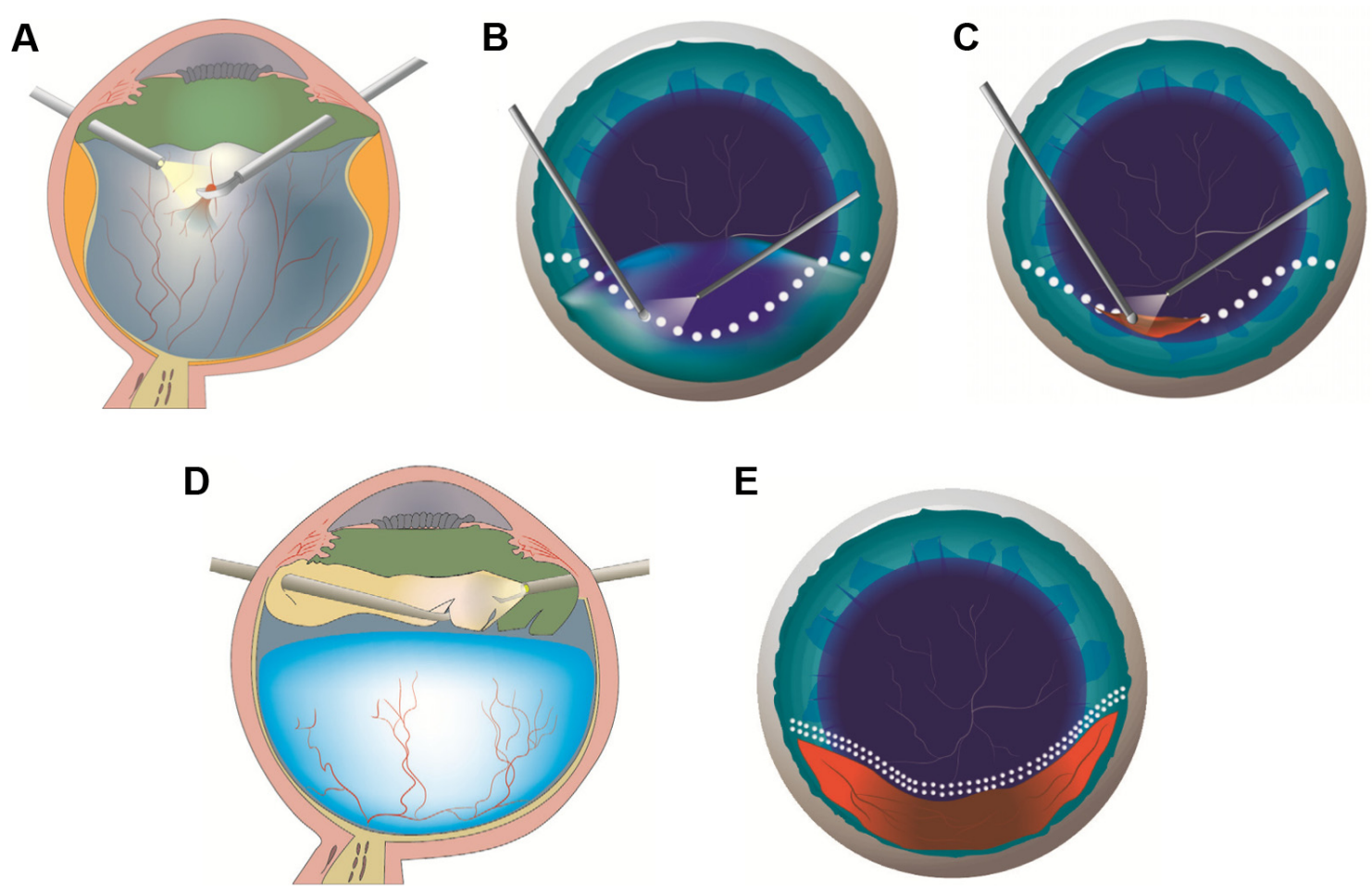

Figure I Procedure of dashed line relaxing retinotomy.

Notes: (A) Complete removal of all the epiretinal or subretinal membrane was done after pars plana vitrectomy. (B) Diathermy was applied to the entire area to be cut in a dashed line pattern. (C) The relaxing retinotomy was completed by gently tearing the dashed line diathermy on the retina under air phase after fluid gas exchange through a preexisting break or a drainage retinotomy. (D) Excision of anterior flap of retinotomy was done under air or silicone oil. (E) Laser endophotocoagulation then can be applied to the edges of the retinotomy, if possible, including the anterior margin of the retinotomy.

treatment of intraocular tamponade, octafluoropropane was used in 24 eyes (44\%), and silicone oil was used in 30 eyes (56\%). Thirteen eyes $(24 \%)$ received intraoperative PFCL to stabilize the anterior retinal flap, and 41 eyes (76\%) underwent dashed line relaxing retinotomy without PFCL due to economic reasons.

Postoperative data are shown separately for the three groups in Table 2. The initial reattachment after operation was noted in 39 of 54 eyes (72\%), and overall, 52 of 54 eyes (96\%) ultimately attained final anatomic reattachment at last examination. The reattachment rate for recurrent RD was not inferior to the others. The postoperative BCVA was improved or remained stable in 39 eyes (72\%) and became worse in 15 eyes (28\%). As expected, primary $\mathrm{RD}$ had the best functional outcome. The average number of additional vitreoretinal surgeries was $0.31 \pm 0.5$. Fifteen of 54 eyes $(28 \%)$ required additional vitrectomy due to recurrent RD with PVR, and 13 eyes had repeated relaxing retinotomy without PFCL use. Secondary glaucoma (IOP $>25 \mathrm{mmHg}$ ) was observed in eight patients (15\%), but no one developed hypotony (IOP $<5 \mathrm{mmHg}$ ) in our study group.

We also identified possible risk factors that may influence the anatomic results after relaxing retinotomy (Table 3 ).
The complex nature of preoperative evaluations such as initial visual acuity, macula involvement, extent of RD, and PVR were not significantly associated with both initial and final reattachment rate. Intraocular tamponade seems to be the only factor associated with initial reattachment $(P<0.001)$ but not with final reattachment $(P=0.497)$. The use or nonuse of intraoperative PFCL did not significantly influence the initial reattachment rate $(P=0.311)$, final reattachment rate $(P=0.427)$, or the postoperative BCVA $(P=0.324)$.

\section{Discussion}

In our study, the initial reattachment rate was $72 \%$, with a final reattachment rate of $96 \%$. Overall BCVA was improved or remained stable in 39 eyes (72\%) and became worse in 15 eyes $(28 \%)$. These anatomical and functional results compare favorably with previous reports of relaxing retinotomy. ${ }^{3,8,11-21}$ Intraocular tamponade was the only factor predictive of initial success. The use or nonuse of intraoperative PFCL did not significantly influence either the reattachment rate or the postoperative BCVA.

Pars plana vitrectomy and retinal tamponade with longacting gas or silicone oil are common surgical procedures in eyes with complicated RD. The Silicone Study reported that 
Table I Baseline patients and characteristics $(n=54)$

\begin{tabular}{ll}
\hline Mean age, SD (range), years & $51.3 \pm 16.2(67)$ \\
Sex, number (\%) & $35(67)$ \\
Male & $17(33)$ \\
Female & \\
Best-corrected visual acuity, number (\%) \\
$\quad$ counting fingers & $21(39)$ \\
Counting fingers & $10(18)$ \\
Hand motions & $21(39)$ \\
Light perception & $2(4)$ \\
Lens status, number (\%) & \\
Phakic & $29(54)$ \\
Pseudophakic & $24(44)$ \\
Aphakic & $1(2)$ \\
Extent of RD, quadrants, number (\%) & \\
S3 quadrants & $20(37)$ \\
4 quadrants & $34(63)$ \\
Macula involvement, number (\%) & \\
Macula on & $14(26)$ \\
Macula off & $40(74)$ \\
PVR classification, number (\%) & \\
Grade C (A) & $26(48)$ \\
Grade C (A+P) & $28(52)$ \\
Diagnosis, number (\%) & \\
Primary RD & $12(22)$ \\
Recurrent RD & $28(52)$ \\
RD secondary to other cause & $14(26)$ \\
(PDR, endophthalmitis, trauma) & \\
Previous surgery, number (\%) & \\
VT + SB & $22(4 \mathrm{I})$ \\
VT & $25(46)$ \\
Cataract extraction & \\
\hline Abbreviations:C (A), & \\
\hline
\end{tabular}

Abbreviations: $C(A)$, grade $C$ proliferative vitreoretinopathy (anterior); $C(A+P)$, grade C proliferative vitreoretinopathy (anterior + posterior); PDR, proliferative diabetic retinopathy; PVR, proliferative vitreoretinopathy; RD, retinal detachment; $\mathrm{SB}$, scleral buckling; SD, standard deviation; VT, vitrectomy.

silicone oil and octafluoropropane were equally effective for eyes receiving retinotomy in vitrectomies for PVR. ${ }^{18}$ Our study concluded that silicone oil tamponade was significantly associated with better initial reattachment rates compared to gas tamponade $(P<0.05)$, which was similar to previous results. ${ }^{15,22}$ Longer effect of intraocular tamponade by silicone oil and decreased dependence on postoperative prone positioning may be superior to gas tamponade when an extended retinotomy is performed. Nevertheless, our findings suggested no significant difference between types of intraocular tamponade and final reattachment, which was compatible with the result of the Silicone Study. ${ }^{18}$ Several publications have concluded that 360 degree relaxing retinotomy is an effective procedure for flattening the retina in complicated RDs. ${ }^{11-13}$ Our study investigated the size of relaxing retinotomy on initial reattachments and finally revealed no statistically significant relationships between them. This result was also comparable with several reports that showed no association between the extent of relaxing retinotomy and the retinal reattachment rate. . $5,16,23^{-23}$ However, the size of the relaxing retinotomy still is associated with the extent of RD and the choice of intraocular tamponade in our study group. Because encircling scleral buckling was previously performed in 17 of 54 eyes (32\%), the relationship between the combined encircling scleral buckling and the retinal reattachment rate could not be evaluated.

Although several publications have reported better anatomical or functional outcomes following the use of intraoperative PFCL, ${ }^{4-10,20}$ our present study demonstrated no significant differences between standard PFCL-assisted relaxing retinotomy and our modified technique using dashed line relaxing retinotomy. Moreover, recurrent instances of PVR in 13 eyes, including five eyes that underwent only vitrectomy and eight eyes that underwent combined vitrectomy with scleral buckling, were successfully repaired by dashed line relaxing retinotomy without intraoperative PFCL and subsequently achieved final reattachment.

Table 2 Anatomic and visual outcome $(n=54)$

\begin{tabular}{|c|c|c|c|c|}
\hline & $\begin{array}{l}\text { Primary RD } \\
n=12\end{array}$ & $\begin{array}{l}\text { Recurrent RD } \\
\mathbf{n}=\mathbf{2 8}\end{array}$ & $\begin{array}{l}\text { RD secondary } \\
\text { to other cause } \\
n=14\end{array}$ & $\begin{array}{l}\text { Total } \\
\mathrm{n}=54\end{array}$ \\
\hline \multicolumn{5}{|l|}{ Success, number (\%) } \\
\hline Initial reattachment & $8(67)$ & $22(79)$ & $9(64)$ & $39(72)$ \\
\hline Final reattachment & II (92) & $28(100)$ & $13(93)$ & $52(96)$ \\
\hline \multicolumn{5}{|l|}{ Postoperative BCVA, number (\%) } \\
\hline Stable or improved & $10(83)$ & $21(75)$ & $8(57)$ & $39(72)$ \\
\hline Worse & $2(17)$ & $7(25)$ & $6(43)$ & $15(28)$ \\
\hline \multicolumn{5}{|l|}{ Postoperative complication, number (\%) } \\
\hline Hypotony (IOP <5 mmHg) & $0(0)$ & $0(0)$ & $0(0)$ & $0(0)$ \\
\hline Secondary glaucoma (IOP $>25 \mathrm{mmHg}$ ) & $2(17)$ & $5(18)$ & I (7) & $8(15)$ \\
\hline
\end{tabular}

Abbreviations: BCVA, best-corrected visual acuity; IOP, intraocular pressure; RD, retinal detachment. 
Table 3 Factors may influence the anatomical outcome

\begin{tabular}{|c|c|c|c|c|}
\hline & $\begin{array}{l}\text { Initial reattachment } \\
\mathrm{n}=39(\%)\end{array}$ & $P$-value & $\begin{array}{l}\text { Final reattachment } \\
n=52(\%)\end{array}$ & $P$-value \\
\hline \multicolumn{5}{|l|}{ Sex } \\
\hline Female & $12(30.8)$ & 0.536 & $17(32.7)$ & 1.000 \\
\hline Male & $27(69.2)$ & & $35(67.3)$ & \\
\hline \multicolumn{5}{|l|}{ Initial BCVA } \\
\hline$\leq \mathrm{CF}$ & $24(6 \mathrm{I} .5)$ & 1.000 & $31(59.6)$ & 0.516 \\
\hline$>C F$ & $15(38.5)$ & & $21(40.4)$ & \\
\hline \multicolumn{5}{|l|}{ Extent of RD } \\
\hline$\leq 3$ quadrant & $15(38.5)$ & 1.000 & $20(38.5)$ & 0.525 \\
\hline 4 quadrant & $24(61.5)$ & & $32(61.5)$ & \\
\hline \multicolumn{5}{|c|}{ Macula involvement } \\
\hline Macula off & $29(74.4)$ & 1.000 & $38(73.1)$ & 1.000 \\
\hline Macula on & $10(25.6)$ & & $14(26.9)$ & \\
\hline \multicolumn{5}{|l|}{ PVR } \\
\hline$C(A)$ & $18(46.2)$ & 0.764 & $25(48.1)$ & 1.000 \\
\hline$C(A+P)$ & $21(53.8)$ & & $27(51.9)$ & \\
\hline \multicolumn{5}{|l|}{ RR size } \\
\hline$<180^{\circ}$ & $27(69.2)$ & 0.302 & $38(73.1)$ & 1.000 \\
\hline$\geq 180^{\circ}$ & $12(30.8)$ & & $14(26.9)$ & \\
\hline \multicolumn{5}{|c|}{ Intraocular tamponade } \\
\hline Silicone oil & $29(74.4)$ & $<0.00 I^{*}$ & $28(53.8)$ & 0.497 \\
\hline $\mathrm{C}_{3} \mathrm{~F}_{8}$ & $10(25.6)$ & & $24(46.2)$ & \\
\hline \multicolumn{5}{|l|}{ PFCL } \\
\hline No PFCL & $28(7 \mid .8)$ & 0.311 & $40(76.9)$ & 0.427 \\
\hline PFCL & II (28.2) & & $12(23.1)$ & \\
\hline
\end{tabular}

Note: *Represents statistical significance.

Abbreviations: $B C V A$, best-corrected visual acuity; $\mathrm{C}_{3} \mathrm{~F}_{8}$, octafluoropropane; $\mathrm{C}(\mathrm{A})$, grade $\mathrm{C}$ proliferative vitreoretinopathy (anterior); $\mathrm{C}$ ( $\left.\mathrm{A}+\mathrm{P}\right)$, grade $\mathrm{C}$ proliferative vitreoretinopathy (anterior + posterior); CF, counting finger; PFCL, perfluorocarbon liquid; PVR, proliferative vitreoretinopathy; RD, retinal detachment; RR, relaxing retinotomy.

Previous reports suggested that hypotony is a possible complication after vitrectomy with relaxing retinotomy, $8,11,12,17-19$ especially in gas-filled eyes. The predictor of postoperative hypotony may be severe anterior PVR with the membrane covering the ciliary body, resulting in ciliary body detachment. ${ }^{24,25}$ In our series, no eyes developed postvitrectomy hypotony after PVR surgery in either group.

PFCL, a substance that is heavier than water or saline, has long been used to reattach the retina posteriorly to anteriorly in complicated RD. PFCL can fixate and stabilize the posterior retina, thereby preventing slippage or inversion of the posterior flap during air exchange. While PFCL is injected into the vitreous cavity during vitrectomy, the subretinal fluid is pushed anteriorly and then into the vitreous cavity through the retinal breaks, which often results in avoiding retinotomy for posterior drainage. ${ }^{4-10}$ However, PFCL is not covered by insurance in our country and is an additional cost burden for patients. If the patient cannot afford PFCL, relaxing retinotomy becomes a difficult task for the surgeon. Our novel technique of dashed line relaxing retinotomy allows us to perform relaxing retinotomy without the help of PFCL. The method has been used in a variety of complicated RDs, including patients with retinal shortening resulting in retinal incarceration or fibrous proliferation and contraction, recurrent RD with PVR, PVR secondary to endophthalmitis, proliferative diabetic retinopathy with extensive anterior periretinal proliferation, and recurrent $\mathrm{RD}$ with anterior retinal displacement after ocular penetrating injury.

Compared to PFCL-assisted relaxing retinotomy, this technique has several limitations: first, a posterior retinotomy sometimes is needed for drainage if the preexisting break cannot allow complete drainage of the subretinal fluid. Second, it is difficult to excise the anterior flap of the retinotomy under air or silicone oil, although surgeons find the procedure easier following practice. Third, there is the possibility of bleeding from the retina or choroid during tearing of the dashed line. Complete occlusion of the retinal vessels in the area of retinotomy and elevation of IOP can decrease the risk of retinal bleeding. Gentle movements and avoidance of pushing the retinal pigment epithelium too much can eliminate the possibility of choroid bleeding. 
In conclusion, relaxing retinotomy is a useful procedure to relieve retinal traction in complicated RD surgery. This modified technique is probably not the first choice when PFCL is available, but our data showed that dashed line relaxing retinotomy achieved similar anatomical and visual outcome compared to PFCL-assisted relaxing retinotomy. Therefore, it may offer an alternative in patients with complicated RD for whom PFCL is not available.

\section{Acknowledgments}

The abstract of this paper was presented at the 55th Annual Meeting of the Ophthalmological Society of Taiwan as a poster presentation with interim findings. The poster's abstract was published in "Poster Abstracts" in 55th Annual Meeting of Ophthalmological Society of Taiwan. The actual paper, however, has never been published.

\section{Disclosure}

The authors do not have any financial conflicts of interest in the subject matter in the manuscript and do not have any commercial or proprietary interest in products mentioned herein. The authors report no conflicts of interest in this work.

\section{References}

1. Machemer R. [Cutting of the retina: a means of therapy for retinal reattachment (author's trans1)]. Klin Monbl Augenheilkd. 1979;175(5): 597-601. German.

2. Machemer R. Retinotomy. Am J Ophthalmol. 1981;92(6):768-774.

3. Machemer R, McCuen BW, de Juan E. Relaxing retinotomies and retinectomies. Am J Ophthalmol. 1986;102(1):7-12.

4. Chang S, Ozmert E, Zimmerman NJ. Intraoperative perfluorocarbon liquids in the management of proliferative vitreoretinopathy. $\mathrm{Am}$ J Ophthalmol. 1988;106(6):668-674.

5. Chang S, Lincoff H, Zimmerman NJ, Fuchs W. Giant retinal tears. Surgical techniques and results using perfluorocarbon liquids. Arch Ophthalmol. 1989;107(5):761-766.

6. Desai UR, Peyman GA, Harper CA. Perfluorocarbon liquid in traumatic vitreous hemorrhage and retinal detachment. Ophthalmic Surg. 1993;24(8):537-541.

7. Millsap CM, Peyman GA, Mehta NJ, et al. Perfluoroperhydrophenanthrene (Vitreon) in the management of giant retinal tears: results of a collaborative study. Ophthalmic Surg. 1993;24(11):759-763.

8. Han DP, Rychwalski PJ, Mieler WF, Abrams GW. Management of complex retinal detachment with combined relaxing retinotomy and intravitreal perfluoro-n-octane injection. Am J Ophthalmol. 1994;118(1):24-32.

Clinical Ophthalmology

\section{Publish your work in this journal}

Clinical Ophthalmology is an international, peer-reviewed journal covering all subspecialties within ophthalmology. Key topics include: Optometry; Visual science; Pharmacology and drug therapy in eye diseases; Basic Sciences; Primary and Secondary eye care; Patient Safety and Quality of Care Improvements. This journal is indexed on
9. Crafoord S, Larsson J, Hansson LJ, Carlsson JO, Stenkula S. The use of perfluorocarbon liquids in vitreoretinal surgery. Acta Ophthalmol Scand. 1995;73(5):442-445.

10. Kertes PJ, Wafapoor H, Peyman GA, Calixto N, Thompson H. The management of giant retinal tears using perfluoroperhydrophenanthrene. A multicenter case series. Vitreon Collaborative Study Group. Ophthalmology. 1997;104(7):1159-1165.

11. Machemer R, Aaberg TM, Freeman HM, Irvine AR, Lean JS, Michels RM. An updated classification of retinal detachment with proliferative vitreoretinopathy. Am J Ophthalmol. 1991;112(2):159-165.

12. Federman JL, Eagle RC. Extensive peripheral retinectomy combined with posterior 360 degrees retinotomy for retinal reattachment in advanced proliferative vitreoretinopathy cases. Ophthalmology. 1990;97(10):1305-1320.

13. Alturki WA, Peyman GA, Paris CL, Blinder KJ, Desai UR, Nelson NC. Posterior relaxing retinotomies: analysis of anatomic and visual results. Ophthalmic Surg. 1992;23(10):685-688.

14. Banaee T, Hosseini SM, Eslampoor A, Abrishami M, Moosavi M. Peripheral 360 degrees retinectomy in complex retinal detachment. Retina. 2009;29(6):811-818.

15. Quiram PA, Gonzales $\mathrm{CR}, \mathrm{Hu} \mathrm{W}$, et al. Outcomes of vitrectomy with inferior retinectomy in patients with recurrent rhegmatogenous retinal detachments and proliferative vitreoretinopathy. Ophthalmology. 2006;113(11):2041-2047.

16. Grigoropoulos VG, Benson S, Bunce C, Charteris DG. Functional outcome and prognostic factors in 304 eyes managed by retinectomy. Graefes Arch Clin Exp Ophthalmol. 2007;245(5):641-649.

17. Morse LS, McCuen BW, Machemer R. Relaxing retinotomies. Analysis of anatomic and visual results. Ophthalmology. 1990;97(5):642647; discussion 647-648.

18. Iverson DA, Ward TG, Blumenkranz MS. Indications and results of relaxing retinotomy. Ophthalmology. 1990;97(10):1298-1304.

19. Blumenkranz MS, Azen SP, Aaberg T, et al. Relaxing retinotomy with silicone oil or long-acting gas in eyes with severe proliferative vitreoretinopathy. Silicone Study Report 5. The Silicone Study Group. Am J Ophthalmol. 1993;116(5):557-564.

20. Bovey EH, De Ancos E, Gonvers M. Retinotomies of 180 degrees or more. Retina. 1995;15(5):394-398.

21. Han DP, Lewis MT, Kuhn EM, et al. Relaxing retinotomies and retinectomies. Surgical results and predictors of visual outcome. Arch Ophthalmol. 1990;108(5):694-697.

22. Shalaby KA. Relaxing retinotomies and retinectomies in the management of retinal detachment with severe proliferative vitreoretinopathy (PVR). Clin Ophthalmol. 2010;4:1107-1114.

23. Tseng JJ, Barile GR, Schiff WM, Akar Y, Vidne-Hay O, Chang S. Influence of relaxing retinotomy on surgical outcomes in proliferative vitreoretinopathy. Am J Ophthalmol. 2005;140(4):628-636.

24. Scott IU, Flynn HW, Murray TG, Feuer WJ; Perfluoron study group. Outcomes of surgery for retinal detachment associated with proliferative vitreoretinopathy using perfluoro-n-octane: a multicenter study. $\mathrm{Am}$ J Ophthalmol. 2003;136(3):454-463.

25. Barr CC, Lai MY, Lean JS, et al. Postoperative intraocular pressure abnormalities in the Silicone Study. Silicone Study Report 4. Ophthalmology. 1993;100(11):1629-1635.

PubMed Central and CAS, and is the official journal of The Society of Clinical Ophthalmology (SCO). The manuscript management system is completely online and includes a very quick and fair peer-review system, which is all easy to use. Visit http://www.dovepress.com/ testimonials.php to read real quotes from published authors. 